DE GRUYTER

OPEN
Beiträge zur Tabakforschung International Contributions to Tobacco Research Volume $26 \cdot$ No. $6 \cdot$ June 2015 DOI: $10.1515 /$ cttr-2015-0018

\title{
ERRATUM NOTICE
}

Volume 26, issue no. 5, 2015, pp. 232-240: An Improved Theoretical Model of Cigarette Smoke Filtration across Mono-Segmented Cellulose Acetate Filters, by Du Wen, Wen Jianhui, Peng Bin, Zhang Xiaobin, Xie Fuwei, Liu Huimin, and Zhong Kejun

The name of the third author is Peng Bin. 